\title{
Teaching English Oral Expressionand Listening Comprehension at the Department ofLetters and English Language, University of Constantine 1: Past and Present Ups and Downs
}

\begin{abstract}
:
This paper gives an overview of how Oral Expression and Listening Comprehension have been taught at the Department of English, University of Constantine, ever since the early eighties to the present time in the new LMD system. It provides a critical analysis of the official syllabi of the classical system and that suggested in the current LMDsystem. Then, it contrasts them with the reality of such teaching at the department. This analysis helps determine the shortcomings of each of the two systems. It also suggests some solutions for a more practical teaching of these two crucial skills in a pedagogical context characterized by ever decreasing linguistic and cultural levels and more and more overcrowded classes.

Key Words: Audio-lingual method, functional approach, language laboratory, language skills, language teaching, listening comprehension, pronunciation, syllabus design, situational English.
\end{abstract}

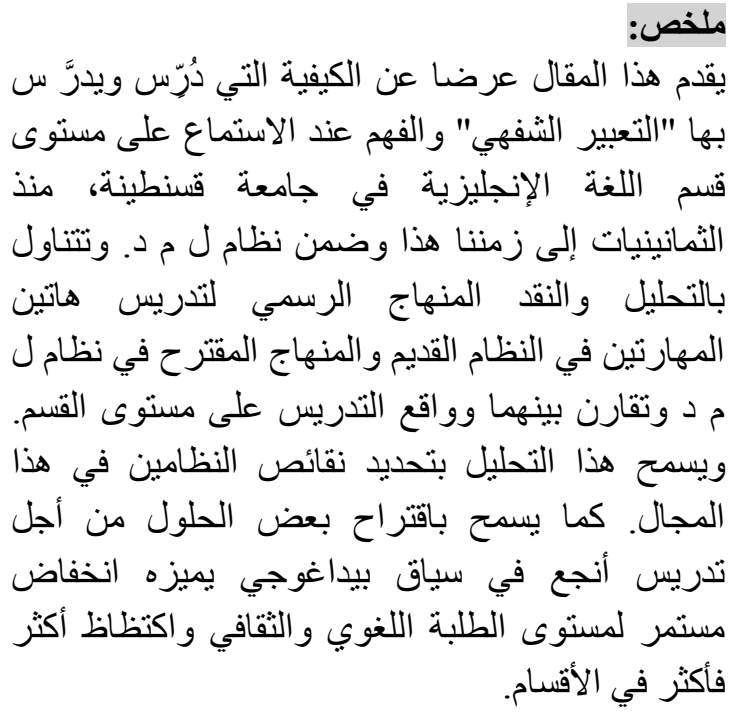

\section{Dr. BEGHOUL Youcef}

Faculty of Letters and Languages

Department of Foreign Languages

University of Mentouri

Constantine

\begin{abstract}
Introduction :
Oral Expression and Listening Comprehension refer to a module that was taught in the classical system's Bachelor of Arts at the Department of English, University of Constantine. Both the subject and the department have now acquired different names as Oral Expression is currentlypart of the module of Language Skills which includes writing, and the Department of English has become Department of Letters and English Language, University of Constantine 1.
\end{abstract}


Thissubject has always contrasted with Written Expression, which was in the past an independent and equally important module; Oral Expression and Listening Comprehensionaimed at inculcating a set of productive and receptive skills. As a student in the classical system, then as a teacher in both the classical and LMD (Licence, Master, Doctorat) systems, the author hasbeen an observer of how it has been taught, and a teacher, by teaching it to classical third-year students for a number of years. The LMDsystem, though supposed to be a major reform of thesyllabus of theBA in English,has not brought much in matter of improving the teaching and the learning of these two crucial skills. The purpose of this paper is to shed light on this state of affair contrasting both the classical and LMD syllabi of Oral Expression and Listening Comprehension with the reality of teaching and learning at the department.

\section{What isOral Expression?}

A search through some reference works and dictionaries for a definition of this long used collocation in the department has yielded nothing for it seems that the two words never collocate in the jargon of modern linguists and applied linguists writing in English. On the other hand, the literal equivalent in French,'expression orale', is very often used in works of pedagogy using the tongue of Molière. The work of Baril and Guillet (1969), for instance, is entitled 'Techniques de l'expressionécrite et orale'.The collocation seems to have been translated word for word from French by the 'syllabus designers' at the Algerian Ministry of Higher Education and Scientific Research of the seventies and introduced in some sketchy syllabus content for teaching BA students of English.When pedagogically related, what is used in English is either the word 'oral' without expression or 'oral skill'. Crystal (1980: 250) in his early attempt at a dictionary of linguistics and phonetics wrote, as part of the entry'oral', that it is:

...the usual adjective for the manifestation of language in its spoken, as opposed to its written form. The term oracy has been coined, on analogy with 'literacy' to refer to ability in speech and listening comprehension, but this term is used more in discussion of language skills and curricula and mother tongue education.

The equivalent of the somewhat idiosyncratic Algerian use of Oral Expression may be found as part of the English technical term 'language skill' 'speaking' or simply 'speech', as in the definition of Crystal above. In their dictionary of language teaching and applied linguistics, Richards and Schmidt (2002:293) defined 'language skills', in the field of language teaching, as:

...the mode or manner in which language is used. Listening, speaking, reading, and writing are generally called the four language skills. Sometimes speaking and writing are called the 
active/productive skills and reading and listening, the passive/receptive skills. Often the skills are divided into subskills, such as discriminating sounds in connected speech, or understanding relations within a sentence.

In reality, it is a term which is far more inclusive than it has been pedagogically credited.It may include, in a formal context,ability to address a hearer or an audience with accuracy at all language levels, starting from the phonological level to the pragmatic one, as well asfluency, style,politeness and subtlety, brevity and conciseness, precision, eloquence, glibness of tongue and coherencein speech. It also contains willingness and frequencyof speech and knowledge of the topic of address.

\section{What is Listening Comprehension?}

Listening Comprehension, on the other hand, is a well attested collocation in the literature on linguistics, theoretical and applied, written in English. Richards and Schmidt (ibid: 313) describe it as follows:

...the process of understanding speech in a first or second language. Thestudy of listening comprehension processes in second language learningfocuses on the role of individual linguistic units (e.g. phonemes, words,grammatical structures) as well as the role of the listener's expectations,the situation and context, background knowledge and the topic. It thereforeincludes both top-downprocessing and bottom-up processing. While traditional approaches to language teaching tended to underemphasizethe importance of teaching listening comprehension, more recentapproaches emphasize the role of listening in building up language competenceand suggest that more attention should be paid to teaching listeningin the initial stages of second or foreign language learning.Listening comprehension activities typically address a number of listeningfunctions, including recognition (focusing on some aspect of the codeitself), orientation (ascertaining essential facts about the text, such as participants,the situation or context, the general topic, the emotional tone, and the genre), comprehension of main ideas, and understanding andrecall of details.

This rendering, although a fairly lengthy one, falls short of providing an exhaustive account of what the task of comprehending speech really entails. It leaves out some elements which are no less crucial. As an instance of this neglect is eye contact and body language in face to face interaction. Oral Expression and Listening Comprehension are only facets of a much more 
complex phenomenon, which is communication. As Halliday (1978: 169) explains, considering communication as a mere exchange of words between parties is too narrow a view for it is a whole "...sociological encounter".Furthermore, and according to Bizell (1989), the success of communication depends on the context where it occurs and it is a feature of its discourse community.

Some general factors play a role in creating difficulties for language learners' to be good listeners (Tinkler, 1980; Boyle, 1984; andFlowerdew and Miller, 1992). These can be text structure and syntax, insufficient exposure to the target language, and a lack of interest and motivation. Brown (1995) argued that these difficulties are also connected to the levels of cognitive demands made by the content of the texts. Besides these issues, problems arising from social and cultural practices have been suggested by Lynch (1997). There are also some specific factors such as speech rate (Conrad, 1989; Blau, 1990; Griffths, 1992; Zhao, 1997), lexis (Johns and Dudley- Evans, 1980; Kelly, 1991), phonological features (Henrichsen, 1984; Matter, 1989)and background knowledge (Markham and Latham, 1987; Long, 1990; Chiang and Dunkel, 1992).

Two of the questions that need to be asked are, given this very complex nature of speaking and listening, can they really be taught in their entirety? What are the elements that are really teachable and what are those that would rely on the learner's personal endeavour?

\section{'Syllabus' for Teaching Oral Expression and Listening Comprehension under the Classical System}

The 'syllabus'of the classical system goes back to the late seventies. It listsa set of objectives for both aspects along with a few suggestions as for the kind of laboratory and classroom activities that would help achieve these objectives. Hence, concerning the Oral Expression aspect, it is stated that:

This part of the course will train the student into developing a certain degree of fluency and being capable to hold intelligent conversation while discussing various topics, expressing personal attitude, and opinions. (Contenu des modules, page $5^{1}$ )

This main objective is split into six objectives:

1. reproduce 'models' of speech with accurate pronunciation, accuracy of sounds, intonation, stress, etc... in everyday modern

\footnotetext{
${ }^{1}$ The original text contains many grammatical and spelling mistakes and, in this paper, they are left as they are.
} 
spoken English. 2. respond with correct grammatical structures and verbal expressions in structural contexts.3. to manipulate grammatical structures and verbal expressions in drills.4. use current language functions appropriately: greetings, varying degrees of curtsey in social situations, evaluations, etc... 5. communicate original thought orally, by means of such activities as discussions or debates on current issues: culture, education, etc... with special emphasis on Algerian realities, for example 'Charter'. At this stage, correct verbal expression including pronunciation and structure is the important criteria.6. initiate free expression of personal attitudes and opinions in various speech situations, with appropriate style and refined choice of words. Here the overall fluency and the manner in which the student expresses nuances of meaning are the performance criteria. (Contenu des modules: page 5)

Up to objective $n^{\circ} 3$, it is the form of language that is primary, including both the syntactic and the phonological aspects. In objective $\mathrm{n}^{\circ} 3$, the method of teaching is implicitly suggested by the use of the word 'drills' i.e., the audio-lingual method. As for objectives 4, 5, and 6, the major concern seems to be the functional aspect of language without neglecting both the stylistic and the semantic features of such functions. There are still some ambiguous concepts within these objectives such as 'original thought' and not least is 'everyday modern spoken English.' Indeed, it seems that there is nothing to which the former is opposed, and the latter refers much more to the written form than to the spoken one. If what is meant by 'modern' is 'present day', then a variety that is used in, say, the streets of London, Liverpool, etc...can hardly be the objective of an academic course.

What follows these objectives is rather a random and incoherent set of activities or exercises: Discussions interviews,situational and functional English (as opposed to structural English), emphasis on grammatical points taught in the grammar module, tenses and sentence structures, basic idioms, elements of phonetics (intonation), and introduction to colloquial English.

The listening comprehension aspect, according to this syllabus:

... is aimed to help the student improve and develop a comprehension of authentic spoken English, and this by exposing him to different forms of speech, to name but a few, expository, conversational, formal, colloquial, etc.... (contenu des modules:Page 1) 


\section{Dr. BEGHOUL Youcef}

Besides the ambiguity of the expression 'authentic spoken English', i.e., whether 'spoken' refers to 'oral' as a medium or to 'colloquial' as a variety, there is the odd listing of 'formal' and 'colloquial' as two varieties along with 'expository' and 'conversational'. The latter two are only aspects of discourse or style that can be achieved in either of the two varieties.

Nine objectives are then listed at which the Listening Comprehension aspect aims:

1. to follow and grasp large stretches of speech at natural speed2. to comprehend the structural arrangement of oral discourse.3. to recognize and comprehend modern terminologies, idioms, and contextual meanings.4. to distinguish between essential and incidental, or redundant features of oral discourse, so as to focus on the main content.5. to recognise style as indicated by stress and intonation patterns.6. to perceive and interpret the meaning of the intonation patterns such as the speaker's mood, attitude, feelings, intonation etc...7. to extract the natural meaning (basic information) from material listened to, that is to be able to identify the topic, general meaning, and be able to summarise a passage.8. to draw the inferential meaning from the literal meaning.9. to evaluate critically the information according to various referents drawing on personal experience, opinions, etc... (Contenu des modules,page 1)

While objectives 1,2,3,6 and 8 are mainly formal, objectives 3, 4, 7, and 9 essentially target the substance of speech.These suggestions are incoherent in the sense that they mix the content with the method. Furthermore, three syllabi are suggested at the same time: The grammatical, the situational, and the functional syllabi. If what is really meant is an eclectic approach that draws from the three of them, it is not explicitly stated.

Finally, a set of exercises and activities are suggested for each of the four years of the BA curriculum, taking into consideration each of the two aspects (Oral Expression and Listening Comprehension) separately. As for Oral Expression, in the first year there are discussions, role selection, lab songs, listening with comprehension to authentic material and pronunciation drills. In the second year, there are free dialogues, language games and technical language; and in the third-year there are public speaking, correction of mistakes and language games and interviews. ConcerningListening Comprehension, in the first year there are graded dialogues/language games, pronunciation drills (practical grammar and phonetics) and guided communicative situations.In the second year, there are introduction to different registers and exposure to different dialects; and in the third-yearthere are BBC programmes, plays (American and English) and T.V programmes. 
In such a sketchy 'syllabus', there is no neat separation of the tasks and activities required to improve the receptive skills (listening) and those required to promote the productive ones (speaking). Hence, technical language is singled out in Oral Expression, for some unknown reasons, after being dealt with in Listening Comprehension within an introduction to different registers. Furthermore, the role of the teacher is mixed with that of the student like 'correction of mistakes'.All in all, these suggestions were sketchy, vague, and far too ambitious (given the teaching facilities and aids available at the time). They do not seem to be based on a clear and definite approach, i.e., a precise theoretical framework.

\section{'Syllabus' for Teaching Oral Expression and Listening Comprehension under the LMD System}

The content of the syllabus of Oral Expression and Listening Comprehension in the new LMD system is even sketchier than that of the classical one. It is written in French, and in what follows is a summarized translation, done by the author of this paper, into English. In the First Semester, what are at stake are some basic teaching units. These are called techniques of Oral Expression and their content is phonetics (learning sounds/laboratory), constructing oral sentences starting from a specified topic, contexts of language use and using language in discursive situations. A second foreign language is introduced in this semester as part of this module! Under this heading there are techniques of both written expression and Oral Expression. In the second, third and fourth semesters, exactly the same objects and content of the first semester reappear. Then, the fifth and sixth semesters are merged into one unit of content and objectives. There is an attempt to specify the content of each of the specialities of the third-year (language sciences; language, literature and civilisation, applied language studies and English for tourism). Yet, the same content of the first two years is repeated with the exception of the general headline which is, for the language sciences option, language comprehension and production in authentic situations; for both the literature and civilisations option and the applied language studies one, it is to get the students accustomed to authentic spoken English and develop their abilities to use language in discursive situations; finally, for the English for tourism option, an extinct option now, it is, once again, to get the students accustomed to authentic spoken English (authentic colloquial RP) and to allow them to develop their abilities to use language in discursive situations. The only difference between the latter objective and that preceding is the very odd variety, put between parentheses, to which the students should be accustomed.

The use of 'techniques of Oral Expression' in this syllabus is rather vague. Are students supposed to be taught about the techniques or how to apply 
those techniques themselves? In either case, nothing whatsoever is mentioned about these techniques. The only allusion made to pronunciation is the first heading of the content which is phonetics (learning sounds/laboratory). Again, a similar question may be raised: is it applied phonetics or is it theoretical phonetics? Whether applied or theoretical, nothing is explicit as to the correlation between phonetics and Oral Expression. An odd concept included in the content is 'oral sentences'. The basic unit of oral discourse is, as is commonly known, the utterance or, technically speaking, the tone group and not the sentence. The latter is a grammatical unit, which is a unit of language as an ideal construct, and is more a part of the written mode than the oral one. Another no less ambiguous expression is the one born in the last heading referring to the situations of language use as 'discursive situations'.

For the last semesters, semesters 5 and 6, the same content of the syllabus of Oral Expression and Listening Comprehension is kept for the three options, but the objectives vary. In the last option, however, both objectives and content differ from the rest. A question that may be asked is: how can the same content be the same for different objectives? In the applied language option and the language applied to the field of tourism, there is, yet, another puzzling term: authentic colloquial RP!!!!! If there is likelihood that the previous odd terms are the result of an unfaithful translation by the author of this paper, it cannot be the case of the latter because it was originally inserted in English in the middle of the French text.

The LMD system, which is supposed to be a radical change in English teaching and learning, has not given due importance to Oral Expression and Listening Comprehension.

\section{Teaching Oral Expression and Listening Comprehensionin Reality}

The author's experience as a student and as a teacher anda questionnaire administered to a group of teachers by the author in his doctoral research (2007) reveal that very few lecturers of this module have taken the general principles of these official 'syllabi' into consideration. Those who have implemented them have done so with great freedom for manoeuvre. The main objective of the course for the teachers is overall comprehension of English which entails an emphasis on receptive skills rather than on productive ones. The approach to teaching is mainly eclectic with a communicative orientation. The language variety used and targeted is Standard British English while differentiating between this variety and the American Standard one through some sort of theoretical input. This does not prevent, in most cases, both teachers and students producing a hybrid variety. The attitude of teachers to errors made by students is that some are harmful and must be eradicated, and some are not so and may be discarded. The ones that need to be corrected are mostly errors of grammar and articulation. They are corrected promptly, 
directly, and explicitly. In most cases, students are reluctant to participate in the discussions, due tointellectual, linguistic and psychological handicaps, which compelthe teachers to participate by more than $50 \%$ in these discussions. In matter of feedback, most of the teachers do not record the students or record themselves as an efficient means of both teaching and self-improvement.

When considering only the mainly used tasks and activities, Oral Expression and Listening Comprehensionhave been taught as follows:

\section{a. Classroom Sessions}

The commonest activity in classroom sessions is making students listen to a text (of various topics) read by the lecturer, generally more than once, then, questions about the content are asked. The material used is mostly authentic. Hand-outs of the printed text are, then, provided to the students, and a general discussion of the gist of the text follows. What is targeted by such an activity is, most of all, the student's intellectual ability to grasp and handle some theoretical issues. Another activity is 'round table chats', in which the lecturer and the students sit in a circle and discuss a given topic. Sometimes, one student or a group of students prepare such a topic at home, and sometimes it is just improvised. The objectives of the latter task are not different from those behind the former one because both tasks drive at the intellectual side of Oral Expression and Listening Comprehension. The only difference between the two is that in the latter the distance between the lecturer and the students is decreased because $\mathrm{s} / \mathrm{he}$ becomes more of a participant than a guide. It is, therefore, hoped that by such 'a face to face' activity, some psychological barriers such as the anxiety of some students would be eased. Finally, few lecturers indulge into some language games and some situational activities such as role-playing, improvised or selected from some books of oral skill teaching.

\section{b. Laboratory Sessions}

The commonest activity is that some material (a conversation, a dialogue, a monologue etc.) is recorded for the students, and, then, some printed questions relating to the recorded material are provided. The students take all their time to look for the answer through a tiringreviewing of the recorded material. So often, in order to motivate the students, the material under probing is an entertaining one like a song.

\section{c. Assessment}

Part of the final assessment of Oral Expressionis a report given to each student separately or to groups of students. The topics of these reports are chosen by either the students themselves or the lecturer. The student or the group of students brieftheir classmates on their topic, and a discussion follows. 
Some lecturers would ask for a written version of the report to be assessed. However, the commonest and main way of assessing Oral Expressionis by a very brief and private 'chat' or a 'tête-à-tête' with each student on either a general topic with prior preparation or on any of the texts or the reports dealt with in the classroom. Concerning Listening Comprehension, it is tested in the laboratory and in exactly the same way as running a regular laboratory session. While some lecturers would be content with the assessment of mainly Oral Expression or mainly Listening Comprehension, few of them would really test both and give as a final mark their average.

This method of teaching Oral Expression and Listening Comprehension is rather exclusive and based on no clear conception of what the two crucial skills of Oral Expression and Listening Comprehension really entail. It is exclusive in the sense that the two skills are reduced to only one or two elements out of their many constituents by overstressing the intellectual and cultural sides. This is at the expense of the equally important sides which are the linguistic and the psychological ones. Indeed, speech is both form and substance, and it seems that the latter has had the lion's share at the expense of the former. Therefore, teaching listening and speaking requires a more inclusive method, which would take into account all the constituents of the two skills, while making the best of the available facilities and equipment.

\section{A Suggested Syllabus for Oral Expression and Listening Comprehension}

Allen (1984:65) wrote:

Since language is highly complex and cannot be taught all at the same time, successful teaching requires that there should be a selection of material depending on the prior definition of objectives, proficiency level, and duration of course.

The best teacher of Oral Expression and Listening Comprehension, as two quite complex skills of an already complex phenomenon (second language acquisition), cannot go, in the best working conditions and with utmost facilities and teaching aids, beyond a small contribution of about a fourth of what should be achieved. The rest lies so much on the student's personal efforts through daily listening, reading, and writing. However, this small contribution by the lecturer is crucial and constitutes a point of departure. A careful and organised planning of the course is part of that small contribution and paves the way for the student to reach a fair level in both listening and speaking. In order to do so, the student has to learn how to get well under control all the elements that make out an oral message. Those elements are of three types: linguistic, intellectual, and psychological.

\section{a. Linguistic Components}


Henrichsen (1984:117) wrote that listeners who have more knowledge of the language system can use it "to compensate for the loss or reduced saliency of portions of the input" created by reduced forms, but those with less knowledge cannot. Hence, linguistic components include a set of phonological, morphological, syntactic, semantic, and pragmatic rules. They also include a certain amount of vocabulary and some stylistic features of the language taught. Such a division of the linguistic components is only theoretical. In practice, however, there may be some borderline areas. There may also be an interaction between the components. For instance, the voicing and the devoicing of the past regular morpheme 'ed' and its realisation as/t/, /d/, or /Id/is a morphophonemic rule which combines both morphology, i.e., how words are structured, and phonology, i.e., how sounds are combined. Some of the linguistic components are of a limited nature such as the phonological, the morphological, and the syntactic ones. Indeed, the inventory of sounds and their possible meaningful combinations (phonology), the possible structures and conversions of words (morphology), as well as the common linear order of words to make sentences (syntax) are limited and rule governed. However, the lexical, semantic, and pragmatic possibilities are unlimited in any language, given the fact that linguistic creativity affects these areas more than others.

\section{Selection}

All the forms and rules that are critical to a mastery of the oral performance ought to be taught and practised. The most important forms would be the phonetic and phonological ones, for those bear directly on the pronunciation aspect, which has been neglected enormously. Although these forms and rules are dealt with within the module of phonetics and phonology, very few students really apply that knowledge in their oral performance. The co-relation between these two modules is seldom emphasized to correct a certain negative attitude of the students to think of the module of phonetics as solely a means to obtain a good mark in the examination. The right choice of the variety of English is crucial, since the very likely occupationof the students, mostly teaching, would require a formal academic use of English; it is either the British standard variety or the American one that ought to be chosen. One can opt for both of them in theoretical accounting and favour one, for practical reasons, in implementation (for instance, the British variety is more economical in matter of articulation). A comparative theoretical input is necessary for the students because so many of them tend to mix both varieties. For example, the letter ' $r$ ' when pre-consonantal and final in a word is, sometimes, pronounced (an American feature), and, sometimes, not (a British one), by the same students. Some students also tend to confuse the standard variety with the regional ones. An instance of such a confusion is the realisation of the voiceless 


\section{Dr. BEGHOUL Youcef}

alveolar stop /t/ asthe voiceless glottal stop /?/when final in monosyllabic words. Such a theoretical input is crucial for the students to develop the ability to code switch in Listening Comprehension.

\section{Grading}

The usual grading of teaching material is from easiest to most difficult or most relevant to least relevant. However, such grading has always run into the subjective problem of finding a standard norm of easiness and difficulty or relevance and irrelevance. An alternative approach would be to focus more on the components that are limited than on those that are limitless. Consequently, a component such as vocabulary ought to be of the least importance given the fact that a great amount of it is only mastered through personal reading and listening. What is of primary importance are the phonological and phonetic rules notably the segmental ones and the mechanisms of connected speech. Indeed, what has been mostly neglectedis the pronunciation aspect. A failure to master the strong and weak forms of syllables and functional words makes the pronunciation of English uneconomical and highly arrhythmic. This failure also influences Listening Comprehension because when the students listen, they expect the same uneconomical and highly arrhythmic pronunciation patterns. Prior to the university and throughout the different stages of their learning of English, most students have got used to a method of teaching that gives primary importance to either syntax or language functions. As a result, a very inaccurate pronunciation is fossilised.

\section{Implementation}

The classroom session would be mainly used for the theoretical aspect. Besides the explanation of the rules, there would be exercises written on the blackboard, and in which all students take part. An instance of such an exercise would be the narrow transcription of a text to which the students have already listened in the laboratory session. This implies that a mastery of the International Phonetic Alphabet (henceforth IPA) is crucial for both the students and the lecturer. The visual representation of the text's pronunciation and of the students' mistakes is more permanent and to which reference is much easier than a recording and some oral comments on pronunciation errors made by the lecturer. The laboratory sessions would be used, for instance, to play out through the room speaker or to show on a screen a previously recorded performance of the students while the lecturer comments on their errors of pronunciation and their strategies in Oral Expression.

\section{Assessment}

Assessing the linguistic component would be to assess all the subelements, the segments, the aspects of connected speech, the syntax, the 
stylistic features, the use of stress and intonation, and, finally, vocabulary, in this order of importance. It is from the most limited and the most teachable ones to the unlimited and the least teachable ones. A mastery of intonation, for instance, relies so much more on a sense of imitation than on a theoretical input. Assessing the students by using the IPA is more objective and with utmost feedback to both the students and the lecturer. For example, dictating a text to the students without any repetitions is assessing their Listening Comprehension; asking them to transcribe that text exactly as they would read it is somehow assessing their oral performance. A transcribed record of their performance not only makes the students understand the reasons behind their marking, but also helps them in a more practical way to learn from their mistakes. Such a 'written' assessment of aural performance ought, of course to be supported by some oral ones because some students tend to be better at speaking than transcribing their speech. Furthermore, an element like intonation cannot appear so obviously on a transcript. Audio or video recording of such a kind of assessment would be even more objective and more beneficial. If Oral performance is audio or video recorded, it helps a lot more in the evaluation and in the correction session when the students listen to themselves. It also allows the lecturer to take all the formal elements into consideration. A five minute 'chatting' or a 'tête-à-tête' with each student, as the students have so often been assessed can only lead to an impressionistic evaluation with very little feedback to the student.

\section{b. Intellectual Components}

Intellectual Components involve the ability to code switch between different English registers, an ability to relate the content of a given material to background information and knowledge, a capacity of grasping, analysing, and digesting an input, and a powerful memory, both short term and long term. Students armed with these intellectual components would understand orally and perform in a much better way than those with little or no background information, with a weak capacity of analysis, and a poor memory, especially the short term one.

The intellectual components are not easy to get under control because they constitute an unlimited aspect. However, the lecturer can help create situations in his teaching, which would help develop such components.

\section{Selection}

Introducing the students to different varieties and different registers with some theoretical input would help the students to code switch in listening. This means they become aware not only of the difference in content but also the difference in form (dialect, standard, etc.). It also helps feed them with a 
fair amount of cultural input. The selection of up to date topics in English used in authentic situations helps in a much better way, than what is commonly done, to develop the student's conception of this language and the culture it vehicles. By authentic situations is not meant the 'pseudo-functional' and the 'pseudo-situational' English that has prevailed in English classes during the seventies, the eighties, and even the nineties and two thousands. This approach consists of introducing students to some neatly recorded material with an artificially slow speed and with over articulation by some actors in a soundproof studio. This kind of material can be of little use to students and merely contributes to creating in their minds a wrong image of not only the language but also the culture. What is meant by authentic situations is, for instance, a hot debate in the British parliament. Such a context of use would introduce the students not only to a sample of the British political life but also make them aware of a certain contrast in the performance of English by conservative MP's from the south and labour MP's from the northern regions.

\section{Assessment}

Assessing the intellectual component would include an assessment of the student's memory of what is essential not of what is superfluous; i.e., the ability to quickly make a 'forest' out of some important 'trees'. If the students are trained to listening to a material, only once, before answering a set of general intelligent questions, they will develop the ability to quickly work out the gist of a message and not to wander in details. Therefore, the nature of the listening task and the kind of questions asked determine to a far extent the type of intellectual and mental faculties assessed. In the Oral Expression test, what can be assessed is, of course, the organisation of the student's thought, his/her reasoning line, the degree of its explicitness and conciseness, and the information output.

\section{c. Psychological Components}

Psychological componentscomprise a certain degree of self-confidence and a certain control of one's anxiety while performing in both skills. They are the most difficult to control for both the learner and the lecturer. The lecturer needs for this purpose to be more of a psychologist. The manner of approaching the students, by decreasing the distance between the teacher and the students and by showing concern to all what they say and do, helps a great deal in breaking the psychic wall of anxiety and lack of confidence that some students build around them. It is crucial for the teacher to know all his students from the start by devising an appropriate information sheet. It is also crucial that the teacher calls all the students by their names (preferably their first ones) because doing it for only some of them will contribute to the isolation of the rest. It is equally important that the students get conscious of their psychic 
weaknesses. Video and audio recording the students while performing would make some of them discover how shy, nervous, and gesticulating they can be in front of an audience and would stimulate them to get control of themselves. Furthermore, if their marks bear this deficiency, and if they are sanctioned, it would help them a great deal in perceiving the importance of getting rid of such handicaps in public speaking. As Wrench et al. (2001) put it, teachers and students have rhetorical and relational goals within the classroom setting. The latter have both academic needs (ability to make good grades) and relational needs (feel affirmed as persons).

\section{Conclusion}

Both the principles and the reality of teaching Oral Expression and Listening Comprehension need many adjustments in order to be more efficient. A content oriented and a student centred approach needs to be replaced by a more formal one that would emphasize on what is limited and teachable and on correcting some wrong assumptions and hypotheses that most students have about the English oral language with its various aspects.

In both listening and speaking, if any of the linguistic components, the intellectual components, or the psychological components is not controlled the message is distorted. Therefore, a course in Oral Expression and Listening Comprehension would have to achieve the objective of making the students control the three sets of components. With the exception of vocabulary and some suprasegmental phonetic rules such as intonation, the linguistic components can be taught, and it is quite possible for the students to reach a fair level of achievements in that aspect. However, the lecturer can only advise and help to create situations in which the intellectual and the psychological sets of components can be developed. Some students, of course, would start from scratch and have to make more efforts than some others who would just build on a fairly good background. An objective and useful evaluation of the student's performance would also have to take these three sets into consideration and not just to focus on the intellectual one, as it has more than often been the case. The three sets of components should bear upon all the different stages of the course design, namely selection, grading, implementation, and assessment. Since the pronunciation of English is not so rule governed and its spelling, for most of the core lexicon, is not as phonetic as that of other languages like French and Arabic, an intensive use of the IPA throughout all the stages of the syllabus is both inevitable and fruitful. The general approach to the syllabus would be eclectic, i.e., it would draw from the three main syllabi namely the functional syllabus, the notional syllabus, and the grammatical one. It is formal and grammatical when dealing with the linguistic components; it is functional and notional when reinforcing the intellectual 
components. The latter approach does not imply the kind of 'pseudo functional' approach that has been current in many parts of the world during the last five decades whereby some very artificial situations in both form and content are created in the classroom. Besides displaying artificiality in both forms and functions, this approach cannot be of much help with large classes, a phenomenon that will probably last for a while at the department of English. Large classes will require a lot more of Information Technology and Communication Technology such as the use of edutainment, an approach that combines entertainment and learning and which has provided tremendous results in producing learners who are more receptive, more accurate and more fluent (Brust, Adriano, and Ricarte 2007).

\section{References}

Allen, J. P. B. (1984). General-purpose language teaching: a variable focus approach. ELT Documents 118/ 61-74. London: PergamonPress

Baril, D. \& Guillet, J., (1969), Techniques de l'expression écrite et orale, Sirey.

Bizzell, P., (1989). Review of the book "The Social Construction of Written Communication". College Composition and Communication 40, 483-486.

Beghoul, Y., (2007). The Interlanguage Phonology of the Undergraduate Students of English at the Department of English, University of Constantine.Unpublished Doctoral Thesis.University of Constantine 1

Blau, E. K. (1990). The effect of syntax, speed, and pauses on listening comprehension. TESOL Quarterly, 24, 746-53.

Boyle, J. (1984). Factors affecting listening comprehension.ELT Journal, 38(41):34-38.

Brown, G. (1995). Dimensions of difficulty in listening comprehension. In D. Mendelshon\& J. Rubin, (Eds.), A Guide for the Teaching of Second Language Listening (pp. 59-73). San Diego: Dominie Press.

Brust, M. R, Adriano, C. M, and Ricarte I. M. L. (2007).Redesigning Computer-based Learning Environments: Evaluation as Communication.International Conference on Education and Information Systems.http://arxiv.org/abs/0706.1127

Chiang, Ch. S., \&Dunkel, P. (1992). The effect of speech modification, prior knowledge, and listening proficiency on EFL lecture learning. TESOL Quarterly, 26, 345-374.

Conrad, L. (1989). The effects of time-compressed speech on native and EFL listening comprehension. Studies in Second Language Acquisition 11:1-16.

Contenu des Modules, a syllabus outline suggested by the Algerian Ministry of Higher Education and Scientific Research in the form of a handout printed in the late 1970's. 
Crystal, D. (1980). A first Dictionary of Linguistics and Phonetics, André Deutsch Limited.

Flowerdew, J. \& Miller, L. (1992).Student Perceptions, problems and strategies in second language lectures.RELC Journal, 23/ 2:60-80.

Griffiths, R. (1992). Speech rate and listening comprehension: Further evidence of the relationship. TESOL Quarterly, 26 (2), 385-390.

Halliday, M.K., (1978). Language as Social Semiotic. Edward Arnold, London.

Henrichsen, L. E. (1984). Sandhi-variation: A filter of input for learners of ESL.

Language Learning, 34, 103-126.

Jason S. W, Richmond V. P., Gorhan J., (2001) Communication, Affect and Learning in the Classroom. Book on Demand, Miami.

Johns, T.F, \& A. Dudley-Evans. (1980). An experiment in team-teaching of overseas postgraduate students of transportation and plant biology. Team Teaching in ESP (ELT Documents 106: 6-23). London: The British Council.

Long, D. R. (1990). What you don't know can't help you: An exploratory study of background knowledge and second language listening comprehension. Studies in Second Language Acquisition, 12, 65-80.

Lynch, T. (1997). Life in the slow lane: Observations of a limited L2 listener. System 25, 385-393.

Matter, J. (1989). Some fundamental problems in understanding French as a foreign language. In: Dechert, H.W. and Raupach, M. (eds.) Interlingual Processes. Gunter Narr, Tübingen, 105-119.

Markham, P. L., \& Latham, M. (1987).The influence of religion-specific background knowledge on listening comprehension of adult second language students.Language Learning, 37, 157-170.

Richards, J. C. \& Schmidt, R. (2002).Longman Dictionary of Language Teaching and Applied Linguistics, Third Edition, Longman.

Tinkler, T. (1980).Learning to teach listening comprehension.English Language Teaching Journal, v35 n1 p28-34

Zhao, Y. (1997). The effects of listeners' control of speech rate on second language comprehension, Applied Linguistics, 18/1: 49-68. 